\title{
Toward the synthesis of thiadiazole-based therapeutic agents: synthesis, spectroscopic study, X-ray analysis, and cross-coupling reactions of the key intermediate 3,5-diiodo-1,2,4-thiadiazole
}

\author{
Mohammed Boulhaoua ${ }^{1} \cdot$ Ana Torvisco $^{2} \cdot$ Tibor Pasinszki $^{1,3}$ (D)
}

Received: 24 September 2019 / Accepted: 18 November 2019 / Published online: 30 November 2019

(c) The Author(s) 2019

\begin{abstract}
The 1,2,4-thiadiazole moiety is an important component of several biologically active compounds, and varying substituents on this aromatic ring is one of the possible methods to develop novel thiadiazole-based drugs for medicine. A key building block to this end, namely 3,5-diiodo-1,2,4-thiadiazole (1), has been synthesized and characterized in this work for the first time. 1 has exhibited high selectivity for the replacement of iodine atom at position C5 (carbon next to sulfur) in Sonogashira-type cross-coupling reactions with phenylacetylene. Therefore, 3-iodo5-(phenylethynyl)-1,2,4-thiadiazole (4) or 3,5-bis(phenylethynyl)-1,2,4-thiadiazole (5) could be synthesized selectively depending on reaction conditions. All three novel molecules have been characterized by NMR, IR, Raman, mass, and UV spectroscopies, and their solid phase structures have been determined by single-crystal $\mathrm{X}$-ray diffraction. 1 is expected to be a key starting material for producing thiadiazole-based therapeutic agents using cross-coupling reactions.
\end{abstract}

Keywords $1,2,4$-Thiadiazoles $\cdot$ Crystal structure $\cdot$ Spectroscopy $\cdot$ Cross-coupling reactions

Electronic supplementary material The online version of this article (https://doi.org/10.1007/s1116 4-019-04047-0) contains supplementary material, which is available to authorized users.

Tibor Pasinszki

tibor.pasinszki@fnu.ac.fj; tpasinszki@caesar.elte.hu

1 Institute of Chemistry, ELTE Eötvös Loránd University, Pázmány P. sétány 1/A, Budapest 1117, Hungary

2 Institute of Inorganic Chemistry, Graz University of Technology, Stremayrgasse 9/V, 8010 Graz, Austria

3 Department of Chemistry, School of Pure Sciences, College of Engineering, Science and Technology, Fiji National University, P.O.Box 7222, Nasinu, Fiji 


\section{Introduction}

Heterocyclic compounds have wide-ranging biological activities, and the 1,2,4-thiadiazole substructure has received increasing attention due to its potential application as insecticides, herbicides, fungicides, and therapeutic agents [1-6]. Ceftaroline fosamil and ceftobiprole medocaril, for example, are recently approved fifth-generation cephalosporin antibiotics [1], and 1,2,4-thiadiazole derivatives have been shown to exhibit anticancer, anti-viral, neuroprotective, and cardioprotective activities [5-7]. 1,2,4-Thiadiazole rings are usually constructed by intra- or inter-molecular cyclization strategies [6-8] during the synthesis of larger biologically active molecules. Another efficient route to produce molecules incorporating the thiadiazole unit could be the replacement of substituent atoms or groups at the 3- and 5-positions of the 1,2,4-thiadiazole moiety. This is especially important for the covalent amalgamation of 1,2,4-thiadiazole with reasonably selected fragments of different biologically active agents, which could lead to compounds with improved activity and selectivity due to synergistic effects $[9,10]$. Therefore, the development of synthetic protocols to this end is of crucial importance. The direct linking of the thiadiazole frame to selected fragments using cross-coupling reactions is expected to be a promising route to novel 1,2,4-thiadiazole derivatives. Key building blocks for these coupling reactions, namely 3,5-diiodo-1,2,4-thiadiazole (1) and 3,5-dibromo-1,2,4-thiadiazole (2), however, are not known to date. Therefore, the original aim of the present work was to find routes to these molecules and to test their applicability in cross-coupling reactions.

In this paper, we report on the first synthesis and structural analysis of $\mathbf{1}$, as well as on its cross-coupling reactions with phenylacetylene. The structure of $\mathbf{1}$ and its coupled products is confirmed by spectroscopy and single-crystal X-ray diffraction. This coupling reaction is the key model reaction for linking potential anticancer agents to the thiadiazole moiety, planned as the continuation of this work.

\section{Experimental part}

\section{General}

All reactions in this work were carried out under an inert nitrogen atmosphere using standard techniques. Chemicals used were reagent grade from commercial sources (Sigma-Aldrich, Fluka) and used without further purification. 3,5-Diamino-1,2,4-thiadiazole (3) was prepared according to a previously published method [11].

NMR spectra of synthesized compounds were obtained on Bruker Avance $250 \mathrm{MHz}$ and Bruker DRX-500 MHz spectrometers using the deuterium signal of the solvent as the lock and tetramethylsilane (TMS) as the internal standard. 
The assignment of all ${ }^{1} \mathrm{H}$ - and ${ }^{13} \mathrm{C}-\mathrm{NMR}$ data necessary for exact structural elucidation of the compounds was based on the cross-peak correlations discernible in 2D-HSQC and HMBC spectra obtained by standard Bruker pulse programs. Infrared (IR) and Raman spectra were recorded on Bruker Alpha and Bruker IFS 55 Fourier transform spectrometers, respectively, using a resolution of $2 \mathrm{~cm}^{-1}$. Spectrophotometric measurements were done using a PerkinElmer UV/Vis Lambda 35 spectrometer applying a slit width of $1 \mathrm{~nm}$ and acetonitrile as solvent. Mass spectroscopic measurements were taken using an Esquire 3000+ (Bruker) ion trap mass spectrometer or an Agilent 5973 Mass spectrometer of a GC-MS instrument. Exact mass measurement was taken on a high-resolution Q-Exactive Focus hybrid quadrupole-orbitrap mass spectrometer (Thermo Fisher Scientific) equipped with heated electrospray ionization source. Samples were dissolved in acetonitrile-water 1:1 (V/V) solvent mixture containing $0.1 \%(\mathrm{~V} / \mathrm{V})$ acetic acid.

\section{Synthesis of 3,5-diiodo-1,2,4-thiadiazole, 1}

Tert-butyl nitrite ( $5 \mathrm{ml}, 4.34 \mathrm{~g}, 43 \mathrm{mmol})$ was added slowly to $\mathrm{CuI}$ (6 g, $31 \mathrm{mmol}$ ) in $45 \mathrm{ml}$ of dry $\mathrm{CH}_{3} \mathrm{CN}$ at room temperature under nitrogen atmosphere. The reaction flask was then heated up using a $70{ }^{\circ} \mathrm{C}$ water bath. 3,5-Diamino-1,2,4-thiadiazole $(1.5 \mathrm{~g}, 13 \mathrm{mmol})$ dissolved in $20 \mathrm{ml}$ of anhydrous DMF was then added to the mixture drop-wise, and the reaction medium was stirred at $70{ }^{\circ} \mathrm{C}$ for $30 \mathrm{~min}$. The reaction was quenched with $220 \mathrm{ml}$ of cold water, and products were extracted with cyclohexane $(3 \times 50 \mathrm{ml})$. The combined organic layer was washed with water $(2 \times 50 \mathrm{ml})$ and dried over anhydrous $\mathrm{MgSO}_{4}$. Filtration and concentration of this latter in vacuo provided a powder-like white solid product (yield: 14\%). M.p.: 129-131 ${ }^{\circ} \mathrm{C}$; NMR $\left(\mathrm{CDCl}_{3}\right.$, r.t.): ${ }^{13} \mathrm{C}-\mathrm{NMR}$ (62.5 MHz): 118.7 (C3), 126.9 (C5) ppm; MS: $337.8[\mathrm{M}]^{+}, 184.9\left[\mathrm{ICNS}^{+}, 126.9 \mathrm{~m} / z[\mathrm{I}]^{+}\right.$; UV-Vis $\left(\lambda_{\max }\right.$, acetonitrile): $237\left(\varepsilon=527 \mathrm{~m}^{2} \mathrm{~mol}^{-1}\right), 261 \mathrm{~nm}$.

\section{Measured spectroscopic data of 3,5-diamino-1,2,4-thiadiazole, 3}

NMR (DMSO-d 6 , r.t.): ${ }^{1} \mathrm{H}-\mathrm{NMR}(250 \mathrm{MHz}): 5.91$ (s, 2H), 7.53 (s, 2H) ppm; ${ }^{13} \mathrm{C}-$ NMR (62.5 MHz): 166.7 (C3), 181.6 (C5) ppm. MS: $117.0 \mathrm{~m} / \mathrm{z}[\mathrm{M}+1]^{+}$; UV-Vis ( $\lambda_{\text {max }}$, acetonitrile): $256\left(\varepsilon=406 \mathrm{~m}^{2} \mathrm{~mol}^{-1}\right), 217(\mathrm{sh}), 199 \mathrm{~nm}$ (see Electronic Supporting Information, ESI).

\section{Synthesis of 5-phenylethynyl-3-iodo-1,2,4-thiadiazole, 4}

Under a nitrogen atmosphere, a 50-ml three-necked flask was charged with $\mathrm{Pd}\left(\mathrm{PPh}_{3}\right)_{2} \mathrm{Cl}_{2}(0.02 \mathrm{~g}, 0.028 \mathrm{mmol}), \mathrm{CuI}(0.02 \mathrm{~g}, 0.1 \mathrm{mmol}), 3,5$-diiodo-1,2,4-thiadiazole $(0.3 \mathrm{~g}, 0.89 \mathrm{mmol})$, phenylacetylene $(0.11 \mathrm{ml}, 0.98 \mathrm{mmol})$, and $\mathrm{Et}_{3} \mathrm{~N}(15 \mathrm{ml})$. The reaction mixture was stirred at $50{ }^{\circ} \mathrm{C}$ for $6 \mathrm{~h}$. After cooling to room temperature, the resulting mixture was evaporated. The crude material was dissolved in chloroform, and the solution was washed with water, dried over anhydrous $\mathrm{MgSO}_{4}$, and evaporated in vacuo. The resulting residue was purified by column chromatography 
using hexane as the eluent (yield: 57\%). M.p.: $66-68{ }^{\circ} \mathrm{C} . \mathrm{NMR}\left(\mathrm{CDCl}_{3}\right.$, r.t.): ${ }^{1} \mathrm{H}-$ NMR (500 MHz): 7.42 (t, $7.6 \mathrm{~Hz}, 2 \mathrm{H}), 7.48(\mathrm{t}, 7.6 \mathrm{~Hz}, 1 \mathrm{H}), 7.61$ (d, $7.6 \mathrm{~Hz}$, 2H); ${ }^{13} \mathrm{C}-\mathrm{NMR}$ (125 MHz): 77.7 (C7), 105.2 (C8), 117.9 (C3), 120.2 (C9), 128.9 (C11,13), 131.1 (C12), 132.5 (C10,14), 171.1 (C5) ppm; MS: 311.9 [M] ${ }^{+}, 184.9$

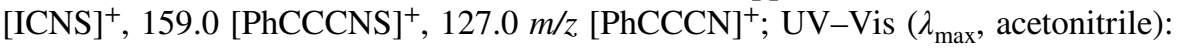
322 (sh), 308, 239 (sh), $227 \mathrm{~nm}$; Raman (neat, characteristic bands): 3068 (vw), 3053 (vw), 2208 (vs), 1596 (m), 1440 (m), 1347 (w), 1254 (m), 1240 (m), 1107 (w), $998(\mathrm{w}), 907(\mathrm{w}), 694(\mathrm{vw}) \mathrm{cm}^{-1}$. See ESI.

\section{Synthesis of 3,5-bis(phenylethynyl)-1,2,4-thiadiazole, 5}

Under a nitrogen atmosphere, a 50-ml three-necked flask was charged with $\mathrm{Pd}\left(\mathrm{PPh}_{3}\right)_{2} \mathrm{Cl}_{2}(0.02 \mathrm{~g}, 0.028 \mathrm{mmol}), \mathrm{CuI}(0.02 \mathrm{~g}, 0.1 \mathrm{mmol}), 3,5$-diiodo-1,2,4-thiadiazole $(0.3 \mathrm{~g}, 0.89 \mathrm{mmol})$, phenylacetylene $(0.24 \mathrm{ml}, 2.22 \mathrm{mmol})$, and $\mathrm{Et}_{3} \mathrm{~N}(15 \mathrm{ml})$. The reaction mixture was stirred at $70{ }^{\circ} \mathrm{C}$ for $10 \mathrm{~h}$. After cooling to room temperature, the resulting mixture was evaporated. The crude material was dissolved in chloroform, and the solution was washed with water and dried over $\mathrm{MgSO}_{4}$. After evaporating the solvent in vacuo, the residue was purified by column chromatography using hexane as the eluent (yield: 64\%). M.p.: $115-117^{\circ} \mathrm{C}$. HR-MS: $287.06379 \mathrm{~m} / \mathrm{z}$ $\left([\mathrm{M}+1]^{+}\right.$; theoretical value: 287.06429$)$; NMR $\left(\mathrm{CDCl}_{3}\right.$, r.t. $):{ }^{1} \mathrm{H}-\mathrm{NMR}(500 \mathrm{MHz})$ : 7.38-7.44 (overlapping m's, 5H), 7.48 (t, 7.6 Hz, 1H), 7.63 (d, 7.6 Hz, 2H), 7.65 (d, $7.6 \mathrm{~Hz}, 2 \mathrm{H}) ;{ }^{13} \mathrm{C}-\mathrm{NMR}$ (125 MHz): 78.6 (C14), 82.1 (C6), 89.6 (C7), 103.7 (C15), 120.5 (C16), 121.1 (C8), 128.7 (C10,12), 128.9 (C18,20), 130.0 (C11), 130.9 (C19), 132.5 (C9,13), 132.7 (C17,21), 157.7 (C3), 169.1 (C5) ppm; UV-Vis ( $\lambda_{\max }$, acetonitrile): 320 (sh), 295, 279, 265 (sh), $228 \mathrm{~nm}$; Raman (neat, characteristic bands): 3062 (w), 2225 (s), 2206 (vs), 1596 (s), 1454 (w), 1418 (m), 1246 (m), 1195 (m), $1097(\mathrm{w}), 999(\mathrm{~m}) \mathrm{cm}^{-1}$ (see ESI).

\section{Single-crystal XRD of 1 and 4}

Single crystals of 1, suitable for XRD analysis, were grown from pentane-chloroform (9:1) and ethanol-chloroform (9.5:0.5) solutions by slow evaporation of the solvent at room temperature (2 days). Crystals prepared using these two solvent mixtures were identical according to XRD. Single crystals of $\mathbf{4}$ were grown from hexane. All crystals suitable for single-crystal X-ray diffractometry were removed from a vial and immediately covered with a layer of silicone oil. A single crystal was selected, mounted on a glass rod on a copper pin, and placed in the cold $\mathrm{N}_{2}$ stream provided by an Oxford Cryosystems cryostream. XRD data collection was performed on a Bruker APEX II diffractometer with use of an Incoatec microfocus sealed tube of Mo K $\alpha$ radiation $(\lambda=0.71073 \AA)$ and a CCD area detector. Empirical absorption corrections were applied using SADABS or TWINABS $[12,13]$. The structures were solved with use of the intrinsic phasing option in SHELXT and refined by the full-matrix least-squares procedures in SHELXL [14-16]. The space group assignments and structural solutions were evaluated using PLATON $[17,18]$. Non-hydrogen atoms were refined anisotropically. 1 was 
refined as a 2-component inversion twin (-100 0-10 00-1) using the TWIN option in SHELXL and refined with a BASF of 0.27. 4 was refined as a 2-component inversion twin (-100 0-10 00-1) using the TWIN option in SHELXL and refined with a BASF of 0.03 . Electrostatic non-covalent inter-molecular interactions [19-22], van der Waals contacts $(\mathrm{C}-\mathrm{H} \cdots \mathrm{X})$ [23-25], and halide interactions ( $\cdots \mathrm{N}$, I...S , I...I) [26-28] were determined by the programs Mercury [29] and Diamond [30] using the centroids and planes and other features of these programs. All values for published compounds were based on a Cambridge Structural Database [31] search, and all values for presented and published compounds fall within expected ranges. All crystal structures representations were made with the program Diamond with all atoms displayed as 30\% ellipsoids. Table 1 contains

Table 1 Crystallographic data and details of measurements for compounds $\mathbf{1}$ and $\mathbf{4}$ Mo $\mathrm{K} \alpha$ $\left(\lambda=0.71073 \AA\right.$ ) $. R_{1}=\Sigma /\left|F_{\mathrm{o}}\right|-\left|F_{\mathrm{c}}\right| /|\Sigma| F_{\mathrm{d}} ; w R 2=\left[\Sigma_{\mathrm{w}}\left(F_{\mathrm{o}}^{2}-F_{2}^{2}\right)^{2} / \Sigma_{\mathrm{w}}\left(F_{\mathrm{o}}^{2}\right)^{2}\right]^{1 / 2}$

\begin{tabular}{|c|c|c|}
\hline Compound & 3,5-Diiodo-1,2,4-thiadiazole (1) & $\begin{array}{l}\text { 3-Iodo-5-phenylethy- } \\
\text { nyl-1,2,4-thiadiazole (4) }\end{array}$ \\
\hline Formula & $\mathrm{C}_{2} \mathrm{I}_{2} \mathrm{~N}_{2} \mathrm{~S}$ & $\mathrm{C}_{10} \mathrm{H}_{5} \mathrm{IN}_{2} \mathrm{~S}$ \\
\hline Fw $\left(\mathrm{g} \mathrm{mol}^{-1}\right)$ & 337.90 & 312.12 \\
\hline$a(\AA)$ & $4.2178(4)$ & $12.5182(4)$ \\
\hline$b(\AA)$ & $7.6624(6)$ & $43.3045(17)$ \\
\hline$c(\AA)$ & 19.5181(17) & $7.8175(4)$ \\
\hline$\alpha\left(^{\circ}\right)$ & 90 & 90 \\
\hline$\beta\left(^{\circ}\right)$ & 90 & 90 \\
\hline$\gamma\left({ }^{\circ}\right)$ & 90 & 90 \\
\hline$V\left(\AA^{3}\right)$ & $630.80(10)$ & $4237.8(3)$ \\
\hline$Z$ & 4 & 16 \\
\hline Crystal size (mm) & $0.03 \times 0.02 \times 0.02$ & $0.05 \times 0.04 \times 0.04$ \\
\hline Crystal habit & Block, colorless & Block, colorless \\
\hline Crystal system & Orthorhombic & Orthorhombic \\
\hline Space group & $P 2{ }_{1} 2_{1} 2_{1}$ & $F d d 2$ \\
\hline$d_{\text {calc }}\left(\mathrm{Mg} \mathrm{m}^{-3}\right)$ & 3.558 & 1.957 \\
\hline$\mu\left(\mathrm{mm}^{-1}\right)$ & 10.18 & 3.18 \\
\hline$T(\mathrm{~K})$ & $100(2)$ & $100(2)$ \\
\hline $2 \theta$ range $\left(^{\circ}\right)$ & $2.9-33.2$ & $3.1-33.1$ \\
\hline$F(000)$ & 592 & 2368 \\
\hline$T_{\min }, T_{\max }$ & $0.318,0.746$ & $0.521,0.747$ \\
\hline$R_{\text {int }}$ & 0.053 & 0.108 \\
\hline $\begin{array}{l}\text { No. of measured and observed } \\
\quad[I>2 \mathrm{~s}(I)] \text { reflections }\end{array}$ & $47,194,1800$ & $128,992,3899$ \\
\hline No. of independent reflections & 1801 & 4069 \\
\hline No. of parameters, restraints & 65,0 & 128,1 \\
\hline$\Delta>_{\max }, \Delta>_{\min }\left(\mathrm{e} \AA^{-3}\right)$ & $0.62,-1.23$ & $0.84,-1.30$ \\
\hline$R 1, w R 2$ (all data) & $R 1=0.0134, w R 2=0.0335$ & $R 1=0.0268, w R 2=0.0605$ \\
\hline$R 1, w R 2(>2 \sigma)$ & $R 1=0.0134, w R 2=0.0335$ & $R 1=0.0244, w R 2=0.0592$ \\
\hline
\end{tabular}


crystallographic data and details of measurements and refinement for compounds 1 and 4.

\section{Quantum chemical calculations}

Quantum chemical calculations were performed using the Gaussian-09 quantum chemistry package [32]. Equilibrium structures of molecules were computed using the B3LYP method and aug-cc-pVTZ basis set on $\mathrm{C}, \mathrm{N}$, and $\mathrm{S}$ atoms and aug-ccpVTZ-pp basis set on I atoms [33]. Vibrational and electronic spectra were then calculated using these minimum energy structures. For characterization of the normal vibrational modes of $\mathbf{1}$, the B3LYP harmonic force field was scaled and the scaled force field was used for the determination of the total energy distribution (TED), which provides a measure of the internal coordinate contributions $[34,35]$.

\section{Results and discussion}

\section{Synthesis and structure of 1}

Based on the perusal of the relevant literature, 3,5-diamino-1,2,4-thiadiazole (3) [11] (ESI) seemed to be a promising precursor for the synthesis of $\mathbf{1}$ and 2. Aqueous phase diazotization reactions, however, led to no avail due to the insolubility of $\mathbf{3}$ in aqueous acidic media, namely aq. $\mathrm{HCl}$, aq. $\mathrm{HBr}$, aq. $\mathrm{HI}$, aq. $\mathrm{H}_{2} \mathrm{SO}_{4}$, and aq. acetic acid. Non-aqueous diazotization of $\mathbf{3}$ using tert-butyl nitrite and $\mathrm{CuI}$ was successful for producing 1 (Scheme 1). 1 was unambiguously identified and characterized by NMR, IR, Raman, mass, and UV-Vis spectroscopies, and the solid phase structure

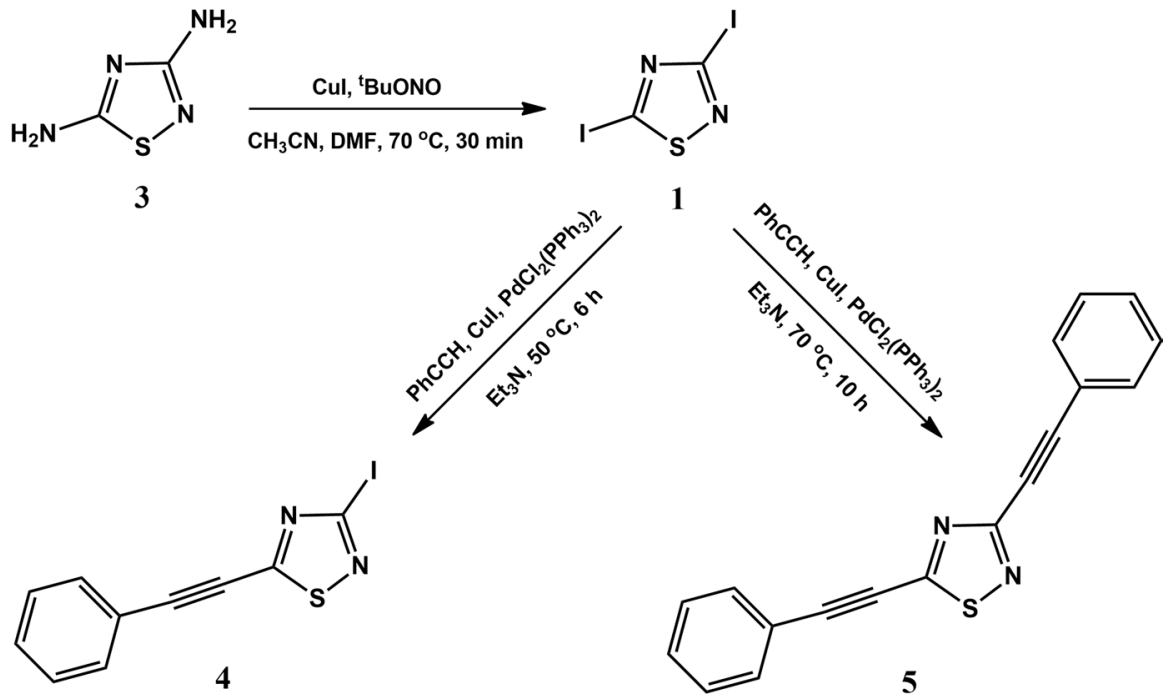

Scheme 1 Synthesis of $\mathbf{1}, \mathbf{4}$, and $\mathbf{5}$ 


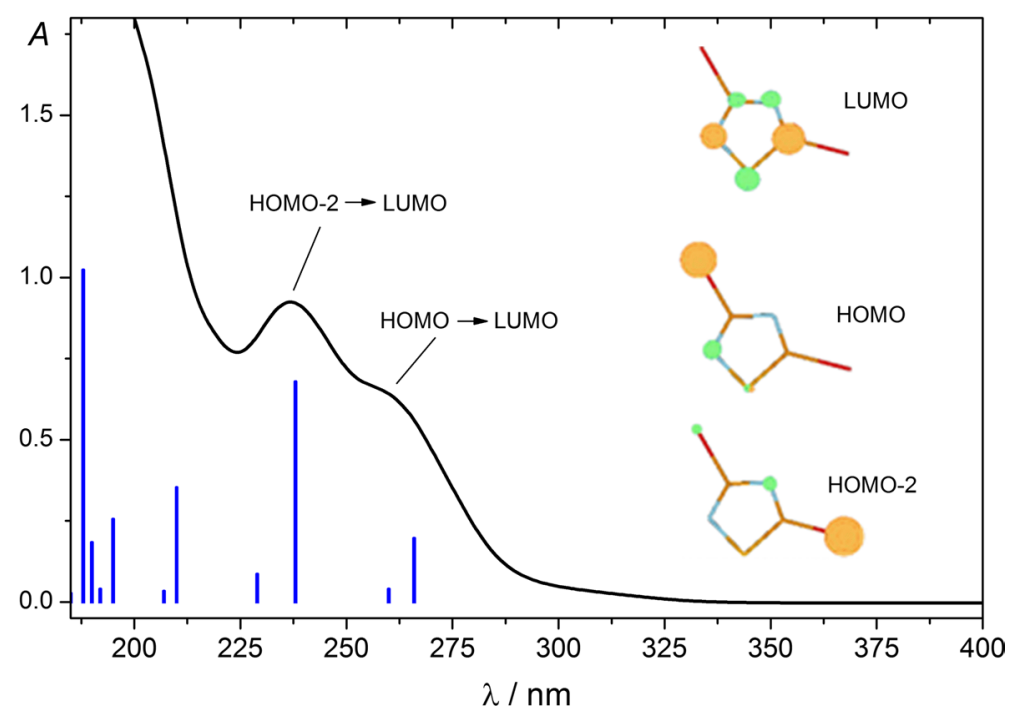

Fig. 1 UV spectrum of 1 in acetonitrile. Blue bars indicate theoretical excitation energies calculated at the TD-B3LYP/aug-cc-pVTZ-pp level (calculated excitation energies are shifted by $-10 \mathrm{~nm}$ for comparison, see Table S1)
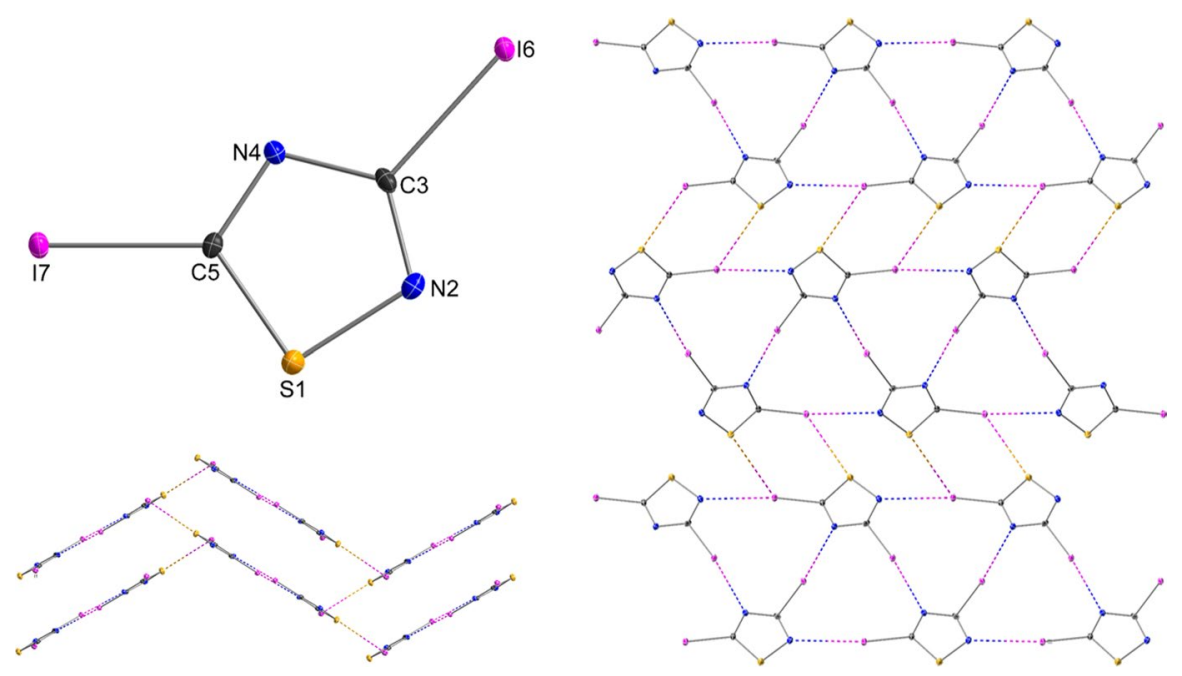

Fig. 2 Structure and crystal packing interactions of $\mathbf{1}$. All atoms are shown as 30\% shaded ellipsoids

was determined by single-crystal X-ray diffraction. We note that it was not possible to synthesize the dibromo derivative, 2, using analogous method and $\mathrm{CuBr}$ or $\mathrm{CuBr}_{2} .1$ is slightly sensitive to prolonged daylight but stable in the dark. It absorbs in the near UV at 237 and $261 \mathrm{~nm}$ corresponding to excitations from a" iodine lone pair orbitals to thiadiazole vacant $\pi$ orbitals ( $n-\pi^{*}$ transitions, see Fig. 1). 
Table 2 Geometric parameters for 3,5-diiodo-1,2,4-thiadiazole (1)

\begin{tabular}{llll}
\hline \multicolumn{3}{l}{ Bond lengths $(\AA)$} & \multicolumn{2}{l}{ Bond angles $\left(^{\circ}\right)$} \\
\hline $\mathrm{I}_{6}-\mathrm{C}_{3}$ & $2.080(4)$ & $\mathrm{N}_{2}-\mathrm{S}_{1}-\mathrm{C}_{5}$ & $92.69(18)$ \\
$\mathrm{I}_{7}-\mathrm{C}_{5}$ & $2.072(4)$ & $\mathrm{C}_{3}-\mathrm{N}_{2}-\mathrm{S}_{1}$ & $107.3(3)$ \\
$\mathrm{S}_{1}-\mathrm{N}_{2}$ & $1.663(4)$ & $\mathrm{C}_{5}-\mathrm{N}_{4}-\mathrm{C}_{3}$ & $108.1(3)$ \\
$\mathrm{S}_{1}-\mathrm{C}_{5}$ & $1.711(4)$ & $\mathrm{N}_{2}-\mathrm{C}_{3}-\mathrm{N}_{4}$ & $119.5(3)$ \\
$\mathrm{N}_{2}-\mathrm{C}_{3}$ & $1.317(5)$ & $\mathrm{N}_{2}-\mathrm{C}_{3}-\mathrm{I}_{6}$ & $123.2(3)$ \\
$\mathrm{N}_{4}-\mathrm{C}_{5}$ & $1.313(5)$ & $\mathrm{N}_{4}-\mathrm{C}_{3}-\mathrm{I}_{6}$ & $117.3(3)$ \\
$\mathrm{N}_{4}-\mathrm{C}_{3}$ & $1.383(6)$ & $\mathrm{N}_{4}-\mathrm{C}_{5}-\mathrm{S}_{1}$ & $112.4(3)$ \\
& & $\mathrm{N}_{4}-\mathrm{C}_{5}-\mathrm{I}_{7}$ & $122.2(3)$ \\
& & $\mathrm{S}_{1}-\mathrm{C}_{5}-\mathrm{I}_{7}$ & $125.4(2)$ \\
\hline
\end{tabular}

The crystal structure of $\mathbf{1}$ is shown in Fig. 2 with geometric parameters listed in Table 2. Compound 1 crystallizes in the orthorhombic space group $P 2{ }_{1} 2_{1} 2_{1}$. 1 has a planar structure $\left(\mathrm{C}_{\mathrm{s}}\right.$ symmetry) and thiadiazole molecules are arranged in zigzag stripes in the solid phase forming weak $\mathrm{I} \cdots \mathrm{N}$ contacts. $\mathrm{I} \cdots \mathrm{N}$ distances, namely 2.995(4) and 3.196(3) $\AA$, are slightly below the sum of van der Waals radii of atoms $(3.53 \AA)$, but $\mathrm{I} \cdots \mathrm{S}$ and $\mathrm{I} \cdots \mathrm{I}$ distances are about the same, 3.7621(1) versus $3.78 \AA$ and 3.9774(4) versus $3.96 \AA$, respectively (see Tables S2 and S3, ESI).

The IR and Raman spectra of $\mathbf{1}$ are shown in Fig. 3, with experimental and computed vibrational frequencies and intensities listed in Table 3 . The 15 normal vibrational modes of 1 transform into $11 \mathrm{a}^{\prime}+4 \mathrm{a}^{\prime \prime}$ vibrational species, all IR and Raman active. All of these fundamentals were identified in IR or Raman

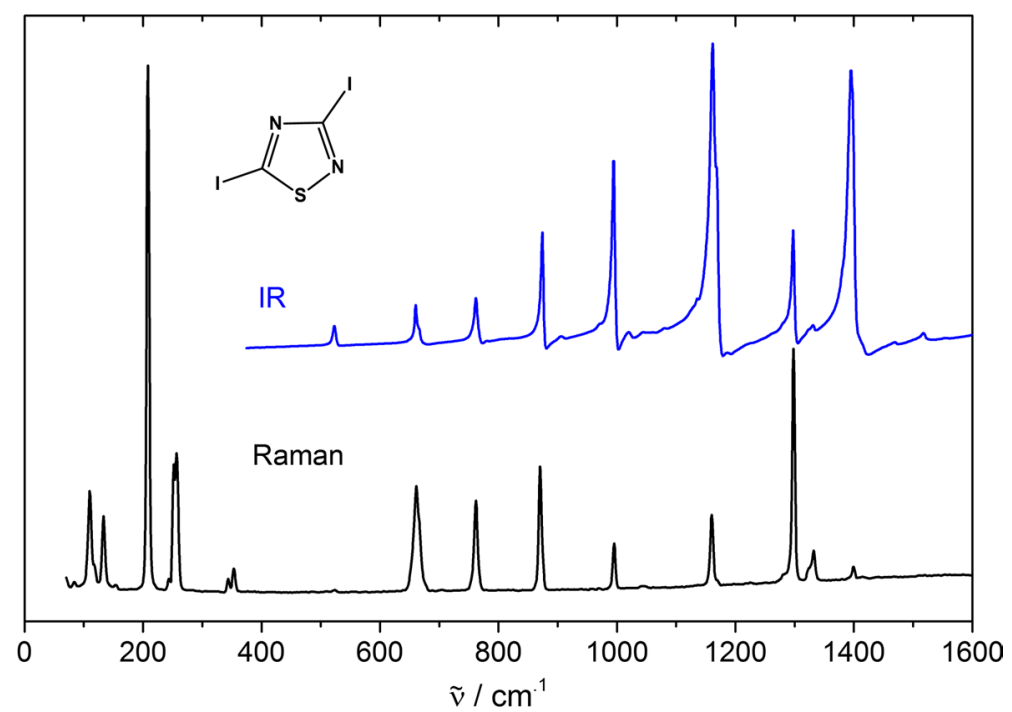

Fig. 3 IR (KBr pellet) and Raman (neat) spectra of 1. See Table 3. Note that band broadening occurs in IR due to relatively large crystallite size even after $30 \mathrm{~min}$ ball milling 
Table 3 Experimental and calculated vibrational wavenumbers $\left(\mathrm{cm}^{-1}\right)$ of 3,5-diiodo-1,2,4-thiadiazole (1)

\begin{tabular}{|c|c|c|c|c|c|}
\hline \multicolumn{2}{|c|}{ Experimental } & \multirow{2}{*}{\multicolumn{3}{|c|}{$\begin{array}{l}\text { Calculated } \\
\text { B3LYP/aug-cc-pVTZ-pp }\end{array}$}} & \multirow[t]{3}{*}{ Assignment and TED $\%^{\mathrm{d}}$} \\
\hline \multirow{2}{*}{$\begin{array}{l}\text { IR } \\
\text { KBr pellet }\end{array}$} & \multirow[t]{2}{*}{ Raman solid } & & & & \\
\hline & & Freq. $^{\mathrm{a}}$ & IR int. ${ }^{b}$ & Raman Int. $^{c}$ & \\
\hline \multirow[t]{3}{*}{1396} & 1399 & 1425 (1409) $a^{\prime}$ & 175.7 & 1.7 & $\nu_{1} 97 \% \mathrm{C}=\mathrm{N}$ st \\
\hline & 1332 & & & & $2 \cdot \nu_{12}$ overtone? \\
\hline & 1322 & & & & $2 \cdot v_{7}$ overtone? \\
\hline 1297 & 1298 & $1318(1305) a^{\prime}$ & 17.1 & 21.4 & $\nu_{2} 96 \% \mathrm{C}=\mathrm{N}$ st \\
\hline 1162 & 1160 & $1140(1147) a^{\prime}$ & 280.7 & 12.3 & $\nu_{3} 80 \% \mathrm{C}-\mathrm{N}$ st, $8 \% \mathrm{rb}, 7 \% \mathrm{C}-\mathrm{I}$ st \\
\hline 994 & 995 & $973(992) \mathrm{a}^{\prime}$ & 65.1 & 11.3 & $\nu_{4} 53 \% \mathrm{rb}, 18 \% \mathrm{~S}-\mathrm{C}$ st, $13 \% \mathrm{C}-\mathrm{I}$ st \\
\hline 874 & 871 & $860(861) a^{\prime}$ & 62.2 & 32.8 & $\nu_{5} 53 \% \mathrm{rb}, 18 \% \mathrm{~S}-\mathrm{C}$ st, $12 \% \mathrm{C}-\mathrm{I}$ st \\
\hline 762 & 762 & $740(760) a^{\prime}$ & 3.3 & 16.2 & $\nu_{6} 85 \% \mathrm{~S}-\mathrm{N}$ st, $8 \% \mathrm{~S}-\mathrm{C}$ st \\
\hline 667 & 667 & $669(654) a^{\prime \prime}$ & 1.2 & 0.2 & $\nu_{12} 74 \% \mathrm{rt}, 25 \% \mathrm{C}-\mathrm{I}$ ob \\
\hline 660 & 661 & $653(657) a^{\prime}$ & 3.8 & 39.8 & $\nu_{7} 43 \% \mathrm{~S}-\mathrm{C}$ st, $44 \% \mathrm{rb}$ \\
\hline \multirow[t]{8}{*}{523} & & $527(517) \mathrm{a}^{\prime \prime}$ & 2.3 & 0.1 & $\nu_{13} 68 \% \mathrm{rt}, 29 \% \mathrm{C}-\mathrm{I}$ ob \\
\hline & 353 & $348(353) a^{\prime}$ & 1.8 & 2.8 & $\nu_{8} 54 \% \mathrm{C}-\mathrm{I}$ st, $18 \% \mathrm{rb}, 27 \% \mathrm{C}-\mathrm{I}$ b \\
\hline & 343 & & & & $\nu_{10}+\nu_{15}$ combination band? \\
\hline & 257 & $248(249) a^{\prime}$ & 2.1 & 31.7 & $\nu_{9} 55 \% \mathrm{C}-\mathrm{I}$ b, $32 \% \mathrm{C}-\mathrm{I}$ st \\
\hline & 252 & $223(220) \mathrm{a}^{\prime \prime}$ & 1.5 & 5.7 & $\nu_{14} 66 \% \mathrm{C}-\mathrm{I}$ ob, $31 \% \mathrm{rt}$ \\
\hline & 208 & $200(204) a^{\prime}$ & 0.4 & 100 & $\nu_{10} 61 \% \mathrm{C}-\mathrm{I}$ st, $15 \% \mathrm{C}-\mathrm{I} \mathrm{b}, 12 \% \mathrm{rb}$ \\
\hline & 133 & $118(116) \mathrm{a}^{\prime \prime}$ & 1.0 & 16.6 & $\nu_{15} 78 \% \mathrm{C}-\mathrm{I}$ ob, $21 \% \mathrm{rt}$ \\
\hline & 110 & $91(91) a^{\prime}$ & 0.3 & 131 & $\nu_{11} 86 \% \mathrm{C}-\mathrm{I} \mathrm{b}$ \\
\hline
\end{tabular}

$s t$ stretching, $r b$ in-plane ring bend, $r t$ out-of-plane ring torsion, $b$ in-plane bend, $o b$ out-of-plane bend, n.o. not observed

${ }^{a}$ Anharmonic vibrational frequencies and vibrational symmetry. Values in parenthesis are obtained by correcting CCSD (T) harmonic vibrational wavenumbers with B3LYP anharmonic corrections. Molecular symmetry is $\mathrm{C}_{\mathrm{s}}$. Isotopes: ${ }^{127} \mathrm{I},{ }^{32} \mathrm{~S},{ }^{12} \mathrm{C},{ }^{14} \mathrm{~N}$. Calculated using aug-cc-pVTZ-pp basis set

${ }^{\mathrm{b}}$ Anharmonic IR intensities in $\mathrm{km} / \mathrm{mol}$

${ }^{\mathrm{c}}$ Relative Raman intensities, calculated using the B3LYP harmonic force field and method described in our previous paper [36]. The relative Raman intensity of $\nu_{10}$ was selected to be 100

${ }^{\mathrm{d}}$ Characterization of the fundamentals; TED (total energy distribution). Only contributions above $5 \%$ are given. The pairs of two $\mathrm{C}=\mathrm{N}$ st, two $\mathrm{C}-\mathrm{I}$ st, two rb, two rt, two $\mathrm{C}-\mathrm{I} \mathrm{b}$, and two $\mathrm{C}-\mathrm{I}$ ob are strongly mixed, therefore their sum contribution is provided in the table

spectra. The calculated frequencies and relative IR and Raman intensities (albeit computed for an isolated molecule) are in good agreement with experiment and support the band assignments. All of the IR/Raman bands observed in the $1600-400 \mathrm{~cm}^{-1}$ region can be assigned to the thiadiazole moiety. The most intensive thus the most characteristic fingerprints of the ring are the IR bands at 1396 and $1162 \mathrm{~cm}^{-1}$ and the Raman band at $1297 \mathrm{~cm}^{-1}$ corresponding to $\mathrm{C}=\mathrm{N}$ and $\mathrm{C}-\mathrm{N}$ stretches (see Table 3). Vibrational bands which originate from the C-I stretches and in- and out-of-plane deformations are observed below $400 \mathrm{~cm}^{-1}$; the most intensive at $208 \mathrm{~cm}^{-1}$ is assigned to $\mathrm{C}-\mathrm{I}$ stretch. 


\section{Cross-coupling reactions of 1}

1 is expected to be an important building block for the construction of larger biologically active thiadiazole derivatives; therefore, it is a logical step to test its performance in cross-coupling reactions. Sonogashira-type cross-coupling reactions have been selected first and phenylacetylene as the model reagent. Cross-coupling in triethylamine solvent has led smoothly and selectively to the mono-substituted product at position five (C5) 4 (Scheme 1). This selectivity can be explained by the lower electron density and thus higher reactivity with nucleophiles at $\mathrm{C} 5$ of the heterocyclic ring, relative to C3 [6]. A plausible mechanism is provided in Scheme S1, ESI. Slightly increasing temperature and reaction time and doubling the phenylacetylene content compared to $\mathbf{1}$ have produced the di-substituted derivative $\mathbf{5}$. Therefore, the synthetic protocol, in general, is appropriate to attach two substituents on the thiadiazole ring as desired in two steps by selecting the order of reagents and reaction conditions. We note that addition of one or two equivalent of $\mathrm{PPh}_{3}$ to the catalyst has not affected the yield of products, but caused difficulties in column chromatographic separation; therefore, application of $\mathrm{PPh}_{3}$ has been rejected in this work. Mass, vibrational, and NMR spectroscopic data have unambiguously identified the products. Ethynyl groups have provided strong and characteristic bands in the Raman spectra (Figure S8, ESI). The comparison of the measured and calculated NMR data unambiguously ruled out substitution at position $\mathrm{C} 3$ for the mono-coupled product (Figure S11, ESI). The structure of $\mathbf{4}$ has also been confirmed by single-crystal X-ray diffraction. Crystallographic data and selected geometric parameters are listed in Tables 1 and S4, respectively. Compound $\mathbf{4}$ crystallizes in the orthorhombic space group $F d d 2.4$ has a planar structure where the phenyl and thiadiazole rings are coplanar with each other (see Fig. 4). Molecules are packed in layers in the solid
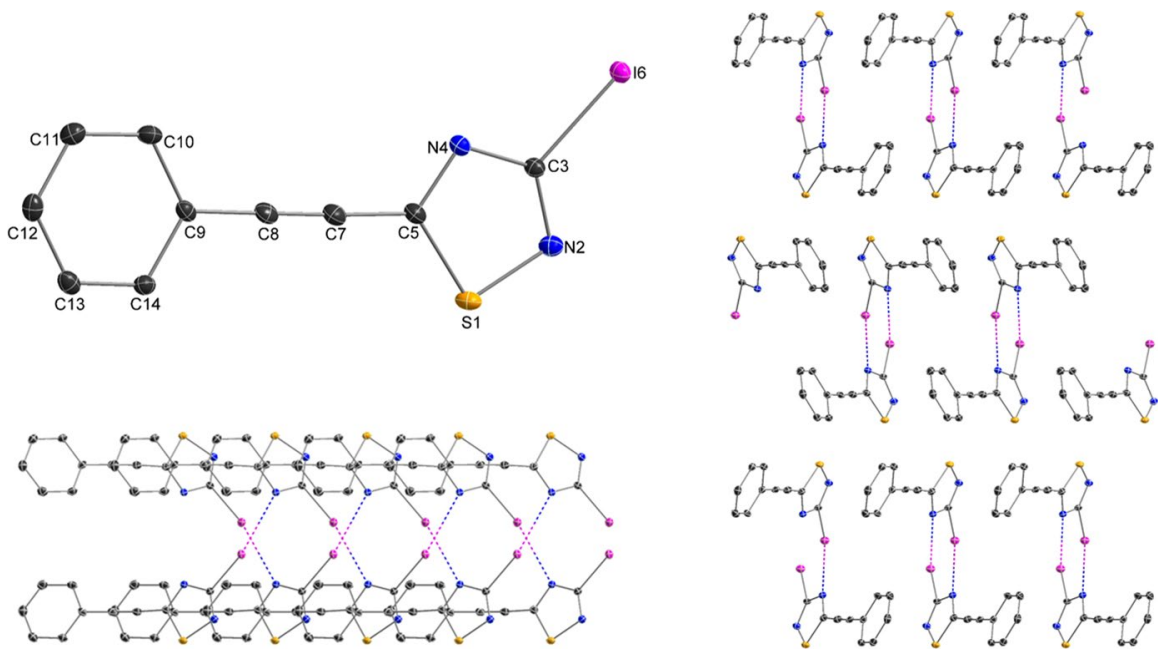

Fig. 4 Structure, crystal packing, and I $\cdots \mathrm{N}$ interactions of $\mathbf{4}$. All atoms are shown as $30 \%$ shaded ellipsoids 


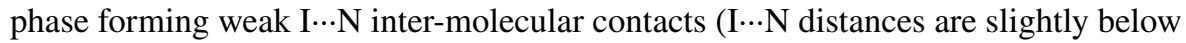
the sum of van der Waals radii of atoms, but I ...S and I...I distances are above typical $\mathrm{I} \cdots \mathrm{S}$ and $\mathrm{I} \cdots \mathrm{I}$ ranges, see Tables S3, S4 and S5, ESI).

Molecules 4 and 5 absorb in the near UV at all wavelengths below $340 \mathrm{~nm}$ (Fig. 5) due to a large number of overlapping UV bands emerging from the delocalized $\pi$-system of the planar molecular structures (confirmed by X-ray diffraction, above, and B3LYP computations, ESI).

\section{Conclusion}

1 can be synthesized from its diamino derivative using non-aqueous diazotization reactions and has been proven to be an effective reagent in Sonogashira-type crosscoupling reactions. In these reactions, the two iodine atoms of $\mathbf{1}$ have been replaced step by step, first at the $\mathrm{C} 5$ position and then at $\mathrm{C} 3$, what provides the possibility for selectively attaching different substituents at the $\mathrm{C} 3$ and $\mathrm{C} 5$ positions of the thiadiazole ring. 1 is thus expected to be an important building block for producing biologically active 1,2,4-thiadiazole derivatives. 1 and its cross-coupled products have been characterized by spectroscopic and diffraction techniques. We note that we have synthesized several phenyl, ethynylferrocenyl, and erlotinib derivatives of $\mathbf{1}$ based on synthetic methods published in this work and initiated the investigation of their antiproliferative effect against tumorous glioma U87 and carcinoma A431 human cell lines with colleagues at the Eötvös Loránd University. According to our preliminary data, both $\mathbf{4}$ and $\mathbf{5}$ were active against carcinoma A431 cell lines and $\mathbf{5}$ was also active against glioma U87 cell growth.

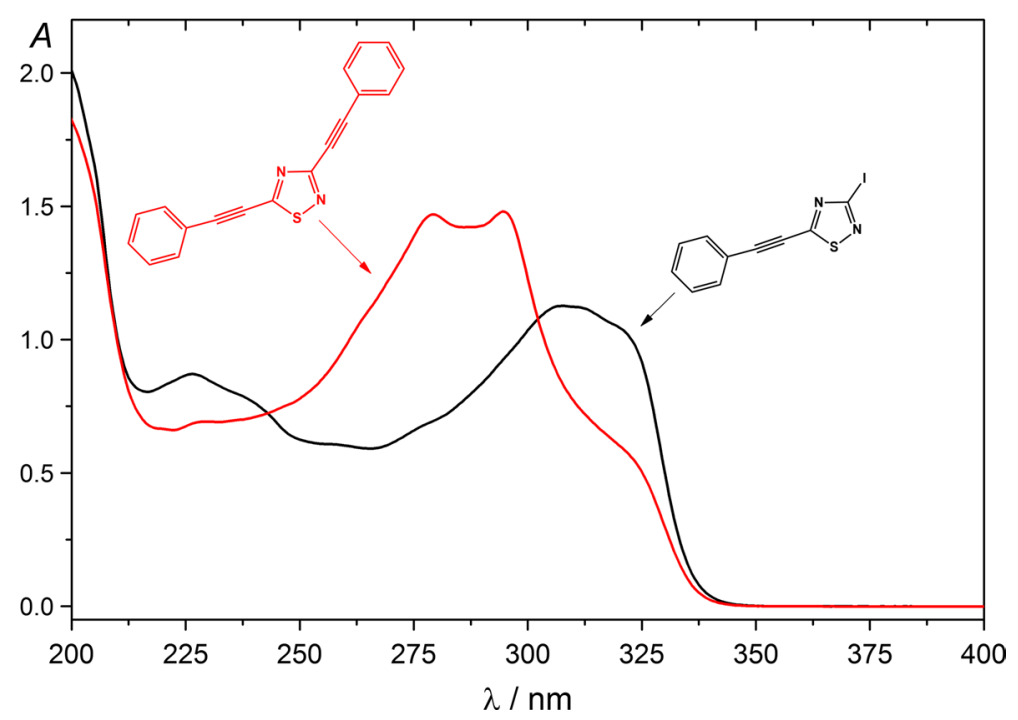

Fig. 5 UV spectra of $\mathbf{4}$ and $\mathbf{5}$ in acetonitrile 


\section{Supplementary material}

Data including NMR, mass, IR/Raman, UV, and crystal structure related to this article are available on the Journal's website. Crystallographic data (excluding structure factors) for the structures in this paper have been deposited with the Cambridge Crystallographic Data Centre as supplementary publication nos. CCDC 1917563 and 1917564 for 1 and 4, respectively.

Acknowledgements Open access funding provided by Eötvös Loránd University (ELTE). We thank the Eötvös Loránd University, Fiji National University, and Graz University of Technology for supporting this research.

\section{Compliance with ethical standards}

Conflict of interest The authors declare that they have no conflict of interest.

Open Access This article is distributed under the terms of the Creative Commons Attribution 4.0 International License (http://creativecommons.org/licenses/by/4.0/), which permits unrestricted use, distribution, and reproduction in any medium, provided you give appropriate credit to the original author(s) and the source, provide a link to the Creative Commons license, and indicate if changes were made.

\section{References}

1. D.L. Hughes, Org. Proc. Res. Dev. 21, 800 (2017)

2. T.F. Tam, R. Leung-Toung, W. Li, M. Spino, K. Karimian, Mini Rev. Med. Chem. 5, 367 (2005)

3. Z. Yang, N. Huang, B. Xu, W. Huang, T. Xie, F. Cheng, K. Zou, Molecules 21, 232 (2016)

4. T. Pasinszki, T. Vörös, G. Vass, G. Tarczay, I. Jalsovszky, J. Mol. Struct. 1179, 118 (2019)

5. G.S.M. Sundaram, S.E. Harpstrite, J.L. Kao, S.D. Collins, V. Sharma, Org. Lett. 14, 3568 (2012)

6. Z.V. Todres, Chalcogenadiazoles, Chemistry and Applications (CRC Press, Taylor and Francis Group, Boca Raton, 2012)

7. A. Castro, T. Castano, A. Encinas, W. Porcal, C. Gil, Bioorg. Med. Chem. 14, 1644 (2006)

8. D.J. Wilkins, P.A. Bradley, Sci. Synth. 13, 277 (2004)

9. N. Kerru, P. Singh, N. Koorbanally, R. Raj, V. Kumar, Eur. J. Med. Chem. 142, 179 (2017)

10. T. Pasinszki, D. Dzsotján, G.G. Lajgut, V. Harmat, A. Bor, I. Zupkó, A. Csámpai, J. Organomet. Chem. 863, 70 (2018)

11. T.V. Melenchuk, E.A. Danilova, M.G. Stryapan, M.K. Islyaikin, Russ. J. Gen. Chem. 78, 480 (2008)

12. Bruker, APEX2 and SAINT (Bruker AXS Inc, Madison, 2012)

13. R. Blessing, Acta Cryst. Sect. A 51, 33 (1995)

14. G. Sheldrick, Acta Cryst. Sect. A 46, 467 (1990)

15. G. Sheldrick, Acta Cryst. Sect. A 64, 112 (2008)

16. G.M. Sheldrick, Acta Cryst. Sect. A: Found. Adv. 71, 3 (2015)

17. A.L. Spek, J. Appl. Cryst. 36, 7 (2003)

18. A.L. Spek, Acta Cryst. Sect. D 65, 148 (2009)

19. C. Janiak, J. Chem. Soc. Dalton Trans.: Inorg. Chem. 21, 3885 (2000)

20. C.A. Hunter, J.K.M. Sanders, J. Am. Chem. Soc. 112, 5525 (1990)

21. E.A. Meyer, R.K. Castellano, F. Diederich, Angew. Chem. Int. Ed. Engl. 42, 1210 (2003)

22. S.K. Nayak, R. Sathishkumar, T.N.G. Row, CrystEngComm 12, 3112 (2010)

23. S. Alvarez, Dalton Trans. 42, 8617 (2013)

24. Y.V. Nelyubina, M.Y. Antipin, K.A. Lyssenko, J. Phys. Chem. A 111, 1091 (2007)

25. R.D. Willett, B. Twamley, W. Montfrooij, G.E. Granroth, S.E. Nagler, D.W. Hall, J.-H. Park, B.C. Watson, M.W. Meisel, D.R. Talham, Inorg. Chem. 19, 7689 (2006) 
26. G.R. Desiraju, R. Parthasarathy, J. Am. Chem. Soc. 111, 8725 (1989)

27. R.D. Gautam, P.S. Ho, L. Kloo, C.L. Anthony, R. Marquardt, P. Metrangolo, P. Politzer, G. Resnati, K. Rissanen, Pure Appl. Chem. 85, 1711 (2013)

28. P. Metrangolo, G. Resnati, IUCrJ 1, 5 (2014)

29. C.F. Macrae, I.J. Bruno, J.A. Chisholm, P.R. Edgington, P. McCabe, E. Pidcock, L. RodriguezMonge, R. Taylor, J. van de Streek, P.A. Wood, J. Appl. Cryst. 41, 466 (2008)

30. H. Putz, K. Brandenburg, Diamond-Crystal and Molecular Structure Visualization, 3.2i; Crystal Impact, Bonn. http://www.crystalimpact.com/diamond

31. F.H. Allen, Acta Crystallogr. Sect. B B58, 380 (2002)

32. M.J. Frisch, G.W. Trucks, H.B. Schlegel, G.E. Scuseria, M.A. Robb, J.R. Cheeseman, G. Scalmani, V. Barone, B. Mennucci, G.A. Petersson et al., Gaussian 09. Revision E.01 (Gaussian Inc, Wallingford, 2013)

33. K.A. Peterson, D. Figgen, E. Goll, H. Stoll, M. Dolg, J. Chem. Phys. 119, 11113 (2003)

34. G. Keresztury, G. Jalsovszky, J. Mol. Struct. 10, 304 (1971)

35. G. Pongor, Program Scale 3 (Department of Theoretical Chemistry, Eötvös Loránd University, Budapest, 1993)

36. T. Pasinszki, M. Krebsz, G. Vass, Chem. Phys. Lett. 487, 194 (2010)

Publisher's Note Springer Nature remains neutral with regard to jurisdictional claims in published maps and institutional affiliations. 